\title{
Preparation and Characteristics of Microencapsulated Lauric Acid as Composite Thermal Energy Storage Materials
}

\author{
Yanghua CHEN *, Yuan LIU, Zhaohe WANG \\ College of Mechatronics Engineering, Nanchang University, Nanchang 330031, China \\ crossref http://dx.doi.org/10.5755/j01.ms.26.1.21303
}

Received 28 August 2018; accepted 29 September 2018

\begin{abstract}
A novel microencapsulated phase change material was prepared by sol-gel method using lauric acid (LA) as core material and titanium dioxide $\left(\mathrm{TiO}_{2}\right)$ as shell material. The composites were characterized by field emission scanning electron microscope (FE-SEM), Fourier transformation infrared spectrometer (FT-IR), differential scanning calorimeter (DSC) and thermogravimetric analyzer (TGA). The results of the FE-SEM and FT-IR indicated that LA was well coated in the shell of $\mathrm{TiO}_{2}$ and no chemical reaction occurred between them. The results of the DSC denoted that the composites with $43.5 \%$ encapsulation ratio of the LA melted at $44.39{ }^{\circ} \mathrm{C}$ with the melting enthalpy of $67.54 \mathrm{~J} / \mathrm{g}$ and solidified at $43.64{ }^{\circ} \mathrm{C}$ with the solidification enthalpy of $65.17 \mathrm{~J} / \mathrm{g}$. The results of the TGA signified that the thermal stability and fire resistance of the microcapsules were greatly enhanced under the protection barrier of $\mathrm{TiO}_{2}$. The thermal decomposition of the microencapsulated LA with $\mathrm{TiO}_{2}$ shell hardly occurred under $200{ }^{\circ} \mathrm{C}$. That is to say, the composites possess good thermal stability in the operating temperature range. In conclusion, the prepared microencapsulated composites can be incorporated into solar energy storage like solar air heaters and into electronic devices as heat sinks.

Keyword: microencapsulated composites, lauric acid, titanium dioxide shell, sol-gel, thermal properties.
\end{abstract}

\section{INTRODUCTION}

Latent heat storage systems are considered as one of the most promising thermal energy storage technology, which depends on the absorption and release of thermal energy by phase change materials (PCMs) [1]. In the past decades, a wide variety of PCMs have been investigated and employed widely in different fields like solar drying systems [2], heating and cooling of buildings [3], industrial waste heat recovery [4], photovoltaic electricity generation [5], domestic refrigerators [6]. Integrating PCMs into solar energy storage system can enhance the operation efficiency by up to $26 \%$ [7]. Meanwhile, the PCMs as heat sink incorporated with electronic devices can prolong lifespan by up to $300 \%$ [8].

Lauric acid is one of the most desirable organic PCMs due to its obvious advantages such as proper phase transition temperature, relatively high heat of fusion, good chemical stability, no toxicity and little supercooling [9]. However, it is difficult to use it directly in thermal energy storage because of its shortcomings like flammability, low thermal conductivity, the leakage of the melted lauric acid and poor thermal stability $[9,10]$. Therefore, microencapsulation technique is the good solution to avoid these drawbacks of lauric acid.

The synthesis methods have been developed to encapsulate micro-sized PCMs droplets with shell materials, for example, emulsion polymerization [11], interfacial polymerization [12], sol-gel process [13], supercritical $\mathrm{CO}_{2}$-assisted methods [14] and complex coacervation [15]. Microencapsulated phase change materials (MPCMs) are prepared by employing the PCMs as core material and using organic or inorganic

\footnotetext{
* Corresponding author. Tel.: +86-13970944938.

E-mail address: 545422685@qq.com (Y. Chen)
}

materials as shell materials. The choice of shell materials plays an important part in regulating the characteristics of the microcapsules, which might influence microstructure, thermal stability, thermal conductivity as well as mechanical strength [16]. In the previous researches reported organic polymeric shell materials such as gelatin formaldehyde resin, melamine-formaldehyde, gelatin-gum Arabic and urea-formaldehyde [17]. This kind of polymeric shell materials have been investigated widely owing to to their good leakproofness and good flexibility, but their disadvantages restrict the wide applications of microencapsulated composites. This is because polymeric shell materials have the unavoidable features of flammability and low thermal conductivity [16]. Especially Some polymeric shells like urea formaldehyde may release poisonous gas that is harmful to environment and health $[10,13]$.

However, using inorganic shell materials to encapsulate PCMs can become a solution to avoid the above disadvantages of organic shell materials. Several studies reported that using inorganic shell materials such as silica [18, 19], $\mathrm{CaCO}_{3}$ [20], AlOOH [21] encapsulated PCMs, but using $\mathrm{TiO}_{2}$ as shell materials is still little reported. Compared with $\mathrm{CaCO}_{3}, \mathrm{TiO}_{2}$ is inherent with good chemical and thermal stability. Studies [22, 23] showed that titanium dioxide $\left(\mathrm{TiO}_{2}\right)$ is higher heat conductivity and better mechanical performances than silica $\left(\mathrm{SiO}_{2}\right)$, which indicated that $\mathrm{TiO}_{2}$ has potential for inorganic shell materials. $\mathrm{TiO}_{2}$ as inorganic shell material can lower the flammability and enhance the thermal stability as well as mechanical strength of the microcapsules [24]. Meanwhile, $\mathrm{TiO}_{2}$ is innocuous and un-poisonous. Fatty acids are good alternatives, which are cheaper than paraffin. For instance, lauric acid can be extracted at low cost from renewable agricultural products such as coconut oil [9]. In this research, the 
main aim is to prepare a novel composites using lauric acid as core material and using $\mathrm{TiO}_{2}$ as shell material by means of sol-gel. And the characterization of the prepared composites will be investigated using FE-SEM, FT-IR, DSC and TGA. By analyzing the results of the above characterizations, the prepared microencapsulated composites which combine the advantages of lauric acid and $\mathrm{TiO}_{2}$ can be utilized in solar energy storage systems such as solar hot water systems and in electronic devices for cooling.

\section{EXPERIMENTAL}

\subsection{Materials}

Lauric acid $\left(\mathrm{C}_{12} \mathrm{H}_{24} \mathrm{O}_{2}\right.$, percentage of purity $\geq 98 \%$, $\mathrm{AR})$ as phase change material was purchased from Aladdin Chemical Reagent CO., Ltd. Tetrabutyl titanate $\left(\mathrm{C}_{16} \mathrm{H}_{36} \mathrm{O}_{4} \mathrm{Ti}\right.$, AR, Aladdin Chemical Reagent CO., Ltd.) was selected as precursor, which can produce titanium dioxide by hydrolysis condensation reaction. Ethyl alcohol $\left(\mathrm{C}_{2} \mathrm{H}_{5} \mathrm{OH}\right.$, AR, Xilong Chemical Reagent Company) and deionized water were acted as solvents. Hydrochloric acid as catalyst and stabilizer( $\mathrm{HCl}, \mathrm{AR})$ was received from Sinopharm Chemical Reagent Co., Ltd. Sodium dodecyl sulfate (SDS) $\left(\mathrm{C}_{12} \mathrm{H}_{25} \mathrm{SO}_{4} \mathrm{Na}\right.$, AR) as $\mathrm{O} / \mathrm{W}$ emulsifier was also obtained from Aladdin Chemical Reagent CO., Ltd.

\subsection{Preparation of micro sized lauric acid droplets $\mathrm{O} / \mathrm{W}$ emulsion}

A certain amount of lauric acid and sodium dodecyl sulfate were added to the $250 \mathrm{ml}$ beaker with deionized water (tabulated in Table 1), and the beaker was placed in a constant temperature magnetic stirring water bath at $65^{\circ} \mathrm{C}$ and the rotational speed of the magnetic force was adjusted to $800 \mathrm{rpm}$ continuing to be $45 \mathrm{~min}$ until the oil/water emulsion was formed.Hydrochloric acid was added drop by drop into the prepared emulsion to adjust the $\mathrm{PH}$ value to $1-2$.

\subsection{Preparation of the MPCMs}

A certain volume of ethyl alcohol and tetrabutyl titanate (tabulated in Table 1) were blended together in another $250 \mathrm{ml}$ beaker to form solution at normal temperature, and the beaker mouth was partially covered with a plastic film. Then it was added to the prepared lauric acid microemulsion drop by drop. At the same time, the temperature and stirring speed of the constant temperature magnetic stirring water bath were controlled at $65^{\circ} \mathrm{C}$ and
$500 \mathrm{rpm}$ lasting $1.5 \mathrm{~h}$. The formation process of the titanium dioxide shell is displayed in Eq. 1, Eq. 2 [24].

The different degrees of hydrolysis reaction of tetrabutyl titanate:

$$
\mathrm{Ti}(\mathrm{OBu})_{4}+n \mathrm{H}_{2} \mathrm{O} \rightarrow \mathrm{Ti}(\mathrm{OBu})_{4} \bullet{ }_{n}(\mathrm{OH}) n+n \mathrm{C}_{4} \mathrm{H}_{9} \mathrm{OH}
$$$$
(n=1,2,3,4)
$$

The structural formula of titanium dioxide oligomers is presented in Fig. 1.

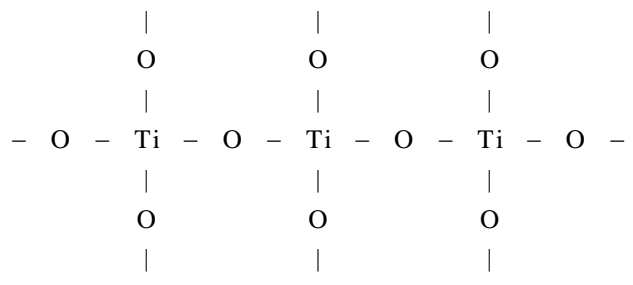

Fig. 1. The structural formula of titanium dioxide oligomers

Under the condition of using ethanol as solvent and hydrochloric acid as catalyst, there were different degrees of hydrolysis reaction of tetrabutyl titanate occurring due to the action between $\mathrm{Ti}$ and $-\mathrm{OH}$ in $\mathrm{H}_{2} \mathrm{O}$ molecule. Then intermolecular condensation reactions occurred in hydrolysis reaction products. And the molecules were further condensed so that the water molecules or alcohol molecules were removed to form the oligomer of titanium dioxide deposited on the surface of lauric acid microemulsion droplets. Finally, the white powder obtained from the experiment named MPCM1-MPCM4 was collected with filter paper and washed with deionized water and ethyl alcohol several times, then dried in vacuum drying oven at $60{ }^{\circ} \mathrm{C}$ for $24 \mathrm{~h}$.

\subsection{Characterization of the MPCMs}

The microscopic morphology of titanium dioxide and microcapsules was observed and analyzed using a field emission scanning electron microscope (FE-SEM, JSM6701F, JEOL, Japan). The chemical structure of lauric acid, titanium dioxide, and microcapsules was analyzed using a Fourier Transform Infrared Spectrometry (FT-IR). A Nicolet5700 was utilized to record the infrared spectrum from $4000 \mathrm{~cm}^{-1}$ to $400 \mathrm{~cm}^{-1}$ with an accuracy of $0.09 \mathrm{~cm}^{-1}$ using $\mathrm{KBr}$ tablets. The thermophysical properties were measured by a differential scanning calorimeter (DSC, NETZSCH5) at a heating or cooling rate of $5{ }^{\circ} \mathrm{C} / \mathrm{min}$ under a nitrogen purge atmosphere of $20 \mathrm{ml} / \mathrm{min}$ [25].

Table 1. The composition of the lauric acid emulsion and solution of the tetrabutyl titanate

\begin{tabular}{|c|c|c|c|c|c|}
\hline \multirow{2}{*}{ Samples } & \multicolumn{3}{|c|}{ Lauric acid emulsion } & \multicolumn{2}{c|}{ Solution of the tetrabutyl titanate } \\
& Lauricacid, $\mathrm{g}$ & Deionized water, $\mathrm{ml}$ & SDS, $\mathrm{g}$ & Tetrabutyl titanate, $\mathrm{g}$ & Anhydrous ethanol, $\mathrm{g}$ \\
\hline MPCM1 & 3 & 60 & 0.5 & 8 & 16 \\
\hline MPCM2 & 4 & 60 & 0.5 & 8 & 16 \\
\hline MPCM3 & 3 & 60 & 0.7 & 8 & 16 \\
\hline MPCM4 & 3 & 60 & 0.5 & 8 & 20 \\
\hline
\end{tabular}

The intermolecular condensation reactions of hydrolysis reaction products:

$$
\begin{aligned}
& (\mathrm{OBu})_{3} \mathrm{Ti}-\mathrm{OH}+\mathrm{HO}-\mathrm{Ti}(\mathrm{OBu})_{3} \rightarrow(\mathrm{OBu})_{3} \mathrm{Ti}-\mathrm{O}-\mathrm{Ti}(\mathrm{OBu})_{3}+\mathrm{H}_{2} \mathrm{O} \\
& (\mathrm{OBu})_{3} \mathrm{Ti}-\mathrm{OBu}+\mathrm{HO}-\mathrm{Ti}(\mathrm{OBu})_{3} \rightarrow(\mathrm{OBu})_{3} \mathrm{Ti}-\mathrm{O}-\mathrm{Ti}(\mathrm{OBu})_{3}+\mathrm{BuOH} .
\end{aligned}
$$


The thermal stability was tested by a thermogravimetric analyzer (TGA4000, PE) from room temperature to $700{ }^{\circ} \mathrm{C}$ at a rate of $20{ }^{\circ} \mathrm{C} / \mathrm{min}$ under the nitrogen atmosphere of $20 \mathrm{ml} / \mathrm{min}$ [13].

\section{RESULTS AND DISCUSSION}

\subsection{Microscopic morphology of the microencapsulated composites}

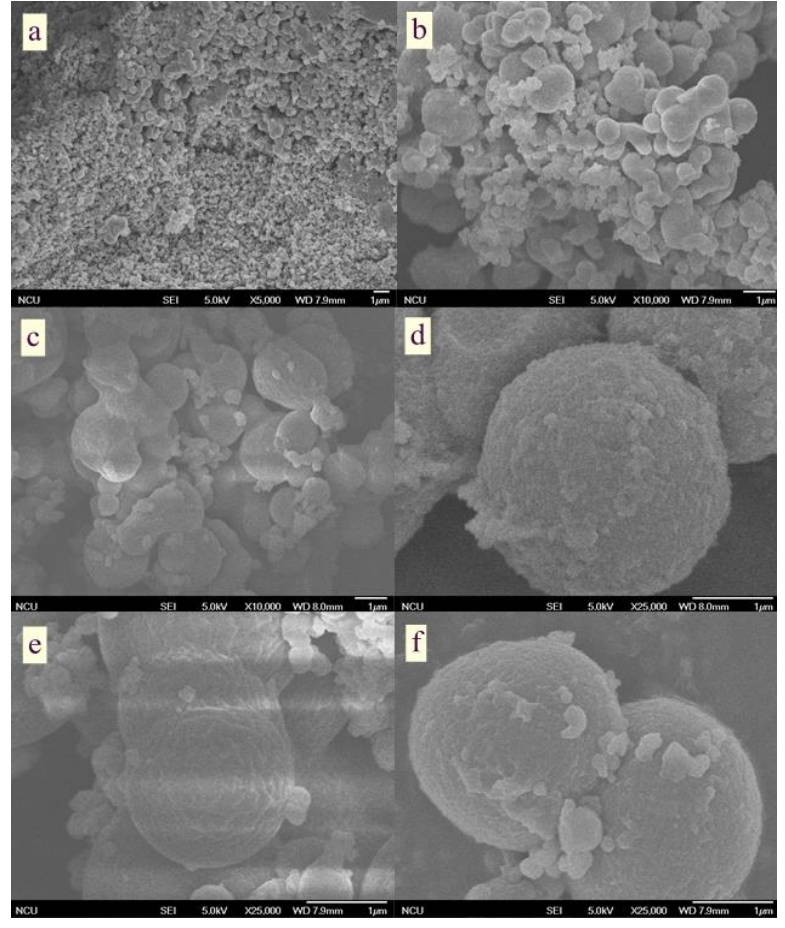

Fig. 2. SEM photographs: $a-\mathrm{TiO}_{2}(5 \mathrm{k} \times)$; $b-\operatorname{MPCM} 1(10 \mathrm{k} \times)$; $\mathrm{c}-\operatorname{MPCM} 2(10 \mathrm{k} x) ; \mathrm{d}-\operatorname{MPCM} 2(25 \mathrm{kx})$;

e-MPCM3(25kx); (f)MPCM4(25kx)

Fig. 2 presents the microstructure of titanium dioxide and four kinds of microcapsules MPCM1-MPCM4. Fig. 2 a displays a microscopic picture of blank titanium dioxide. Titanium dioxide particles have very large specific surface area at the micron level. As shown in Fig. 2 b-f, it can be seen that lauric acid is well encapsulated by titanium dioxide into micron sized spherical particles or particle clusters. Similar results were observed in the previous research on microencapsulated paraffin with titanium dioxide shell [24].

\subsection{FT-IR analysis of the microencapsulated composites}

Fig. 3 exhibits the FT-IR spectra of the lauric acid, titanium dioxide and MPCM1-MPCM4. Fig. 3 a displays the spectrum of the lauric acid. The peak at $3449.27 \mathrm{~cm}^{-1}$ denotes the stretching vibration of $-\mathrm{OH}$ group [15]. The peaks at $2921.19 \mathrm{~cm}^{-1}$ and $2852.17 \mathrm{~cm}^{-1}$ are attributed to the asymmetric and symmetric stretching vibration of its $-\mathrm{CH}_{2}$ group [13]. The peak at $1700.50 \mathrm{~cm}^{-1}$ is assigned to the stretching vibration of $\mathrm{C}=\mathrm{O}$. The peaks at $937.97 \mathrm{~cm}^{-1}$ and $723.75 \mathrm{~cm}^{-1}$ signify the out-of-plane bending vibration of $-\mathrm{OH}$ group and $\mathrm{C}-\mathrm{H}$, respectively [25]. Fig. 3 b displays the spectrum of the $\mathrm{TiO}_{2}$. The stretching vibration of $-\mathrm{OH}$ group in $\mathrm{H}_{2} \mathrm{O}$ is shown at $3418.98 \mathrm{~cm}^{-1}$ [24]. The peaks at
$2924.33 \mathrm{~cm}^{-1}$ and $2851.56 \mathrm{~cm}^{-1}$ are assigned to the asymmetric and symmetric stretching vibration of its $-\mathrm{CH}_{2}$ group in absolute ethyl alcohol [13]. And the peak at $1384.21 \mathrm{~cm}^{-1}$ results from the in-plane bending vibration of $-\mathrm{CH}_{3}$ group. The peak at $1622.52 \mathrm{~cm}^{-1}$ presents the deformation vibration of the $-\mathrm{OH}$ group in $\mathrm{H}_{2} \mathrm{O}$. The characteristic peak of titanium dioxide does not appear in the diagram because it is in the far infrared region. The result is consistent with that of this literature [24].

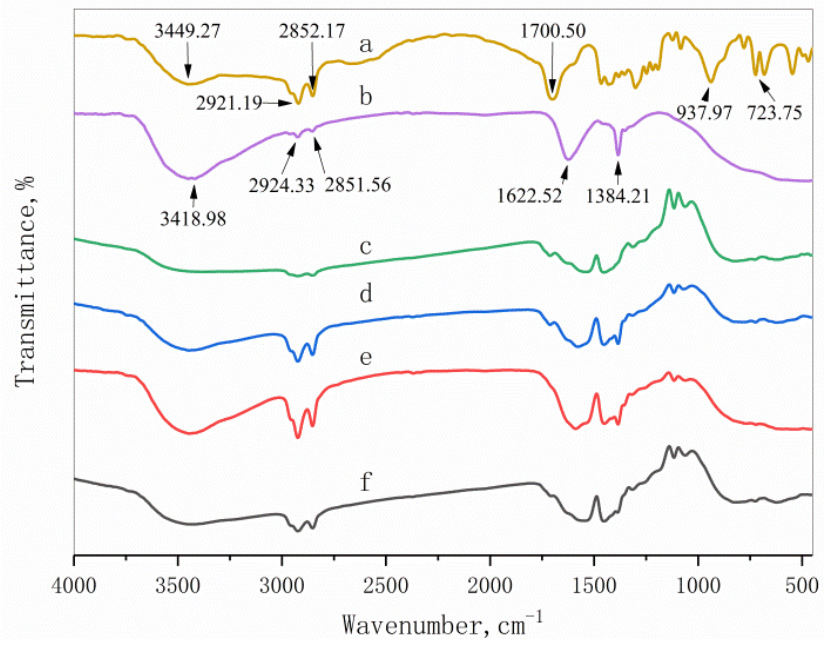

Fig. 3. FT-IR spectrum: a-lauric acid; b- $\mathrm{TiO}_{2} ; \mathrm{c}-\mathrm{MPCM} 1$; d-MPCM2; e-MPCM3; f-MPCM4

As presented in Fig. $3 \mathrm{c}$ and $\mathrm{f}$, the absorption peaks of lauric acid and $\mathrm{TiO}_{2}$ are observed in the spectrum of MPCM1-MPCM4. Based on this result that is no peak shift and occurring, it is confirmed that no chemical reaction occurring between lauric acid and $\mathrm{TiO}_{2}$ shell.

\subsection{Thermal properties of the microencapsulated composites}

Fig. 4 and Fig. 5 shows the DSC graphs of the lauric acid and the microcapsules. The thermal properties parameters are listed in Table 2. It can be seen from Fig. 4 and Fig. 5 that both lauric acid and microcapsules have only one endothermic peak and one exothermic peak, and the microcapsules have similar thermal performance curves.

Table 2. DSC data of the lauric acid and MPCM1-MPCM4

\begin{tabular}{|c|c|c|c|c|c|}
\hline \multirow{2}{*}{ Samples } & \multicolumn{2}{|c|}{ Melting } & \multicolumn{2}{c|}{ Solidifying } & Encapsulation \\
\cline { 2 - 5 } & $\mathrm{T},{ }^{\circ} \mathrm{C}$ & $\begin{array}{c}\text { Latent } \\
\text { heat, } \mathrm{J} / \mathrm{g}\end{array}$ & $\mathrm{T},{ }^{\circ} \mathrm{C}$ & $\begin{array}{c}\text { Latent } \\
\text { heat, } \mathrm{J} / \mathrm{g}\end{array}$ & $\begin{array}{c}\text { ratio of the } \\
\text { lauric acid, \% }\end{array}$ \\
\hline $\begin{array}{c}\text { Lauric } \\
\text { acid }\end{array}$ & 44.53 & 155.27 & 42.39 & 152.64 & 100.00 \\
\hline MPCM1 & 44.77 & 34.85 & 43.58 & 32.57 & 22.44 \\
\hline MPCM2 & 44.39 & 67.54 & 43.64 & 65.17 & 43.50 \\
\hline MPCM3 & 44.20 & 35.79 & 43.78 & 33.64 & 23.05 \\
\hline MPCM4 & 44.67 & 38.94 & 43.36 & 37.28 & 25.17 \\
\hline
\end{tabular}

As shown in Table 2, the melting temperature of lauric acid, MPCM1, MPCM2, MPCM3, MPCM4 is $44.53^{\circ} \mathrm{C}$, $44.77{ }^{\circ} \mathrm{C}, 44.39{ }^{\circ} \mathrm{C}, 44.20{ }^{\circ} \mathrm{C}, 44.67{ }^{\circ} \mathrm{C}$, respectively, and the solidification temperature of lauric acid, MPCM1, MPCM2, MPCM3, MPCM4 is $42.39^{\circ} \mathrm{C}, 43.58^{\circ} \mathrm{C}$, $43.64{ }^{\circ} \mathrm{C}, 43.78^{\circ} \mathrm{C}, 43.36{ }^{\circ} \mathrm{C}$, respectively. 


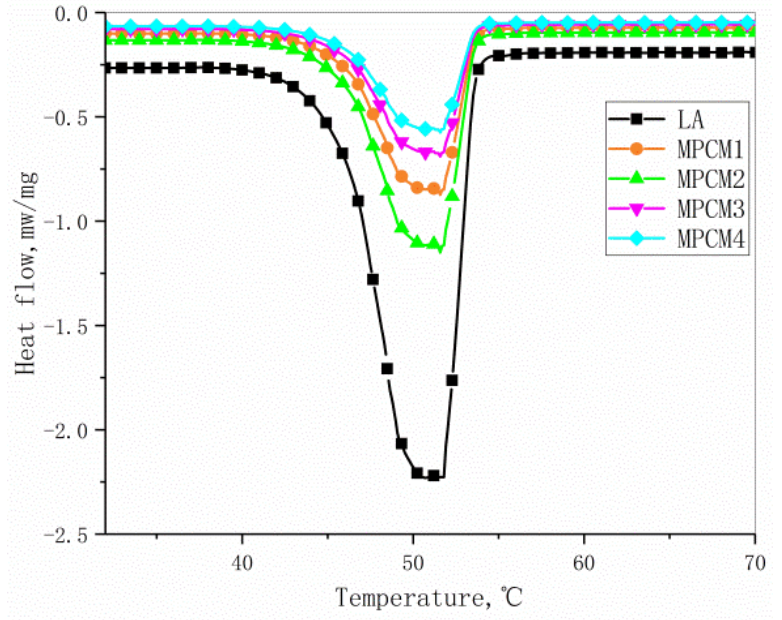

Fig. 4. The melting DSC graphs of the lauric acid, MPCM1, MPCM2, MPCM3 and MPCM4

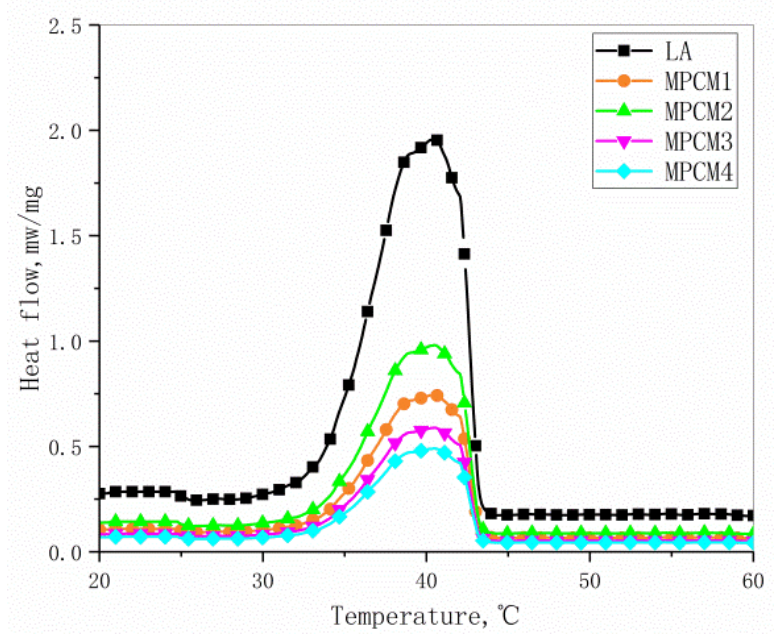

Fig. 5. The solidifying DSC graphs of the lauric acid, MPCM1, MPCM2, MPCM3 and MPCM4

The difference between the melting temperature and the solidification temperature of the lauric acid and the microcapsules are $2.14{ }^{\circ} \mathrm{C}, 1.19^{\circ} \mathrm{C}, 0.75^{\circ} \mathrm{C}, 0.45^{\circ} \mathrm{C}$ and $1.31^{\circ} \mathrm{C}$ by calculation. The decrease of supercooling degree of microcapsules can be attributed to the good thermal conductivity of $\mathrm{TiO}_{2}$ shell [22], which makes it act as nucleating agent during the solidification process of the microcapsules.

The encapsulation efficiency of lauric acid in microencapsuled composite phase change material can be calculated by Eq. 3 [34]:

$\eta \%=\frac{\triangle H_{M P C M}}{\Delta H_{P C M}} \times 100 ;$ where $\eta$ is the encapsulation efficiency of the lauric acid in the microcapsules, $\Delta H_{\mathrm{PCM}}$ represents the melting enthalpy of the lauric acid $(\mathrm{J} / \mathrm{g}), \triangle H_{\mathrm{MPCM}}$ represents the melting enthalpy of the microcapsules as measured $(\mathrm{J} / \mathrm{g})$.

The encapsulation efficiency of lauric acid in the microcapsules was also listed in Table 2. It can be found that the value of lauric acid in the MPCM2 is larger than that in the MPCM1, MPCM3 and MPCM4. It can be explained that the larger mass ratio of the LA in the microcapsules is, the higher enencapsulation ratio of the microcapsules have. The difference of the encapsulation efficiency between MPCM1 and MPCM4 can be explained the amount of anhydrous ethanol, which influences the hydrolysis polycondensation reaction rate of tetrabutyl titanate [24].

Table 3 displays comparison of thermal properties between the prepared microcapsules and other microcapsules in literatures. Comparing other MPCMs in Table 3, the $\mathrm{LA} / \mathrm{TiO}_{2}$ microcapsules poesses a larger latent heat. It is found that these MPCMs have similar phase change temperature range within $40-80^{\circ} \mathrm{C}$ for solar energy storage.

\subsection{Thermal stability of the microencapsulated composites}

Fig. 6 presents the TGA graphs of the lauric acid, $\mathrm{TiO}_{2}$, MPCM1, MPCM2, MPCM3, MPCM4.The onset temperature of the mass loss $\left(\mathrm{T}_{\text {onset }}\right)$, the temperature of maximum weight loss rate $\left(\mathrm{T}_{\text {oeak }}\right)$ and the charred residue amount of the $\mathrm{LA}, \mathrm{TiO}_{2}$ and the MPCMs are exhibited in Table 4. As presented in Fig. 6, it is clear that the microcapsules display similar thermal stability characteristics and the TGA graphs of the microcapsules are much gentler compared to that of LA. The results are in accordance with that of relevant literature [17, 19, 23]. The charred residue amount of the empty $\mathrm{TiO}_{2}$ is much larger than those of the microcapsules, which is indicated that $\mathrm{TiO}_{2}$ possess good thermal stability and fire resistance. The residual amount of MPCM2 is smaller than that of MPCM1, MPCM3, MPCM4, because the content of lauric acid in MPCM2 is the largest, that is to say, the content of the titanium dioxide shell in MPCM2 is the least. It is indicated that the protective effective of $\mathrm{TiO}_{2}$ shell is restricted due to its content in microcapsules. The residue amount of lauric acid is close to zero at $373{ }^{\circ} \mathrm{C}$, but the residue amount of $\mathrm{TiO}_{2}$, MPCM1, MPCM2, MPCM3, MPCM4 is $76.48 \%, 60.01 \%, 58.59 \%, 67.5 \%, 61.59 \%$. This is the fact that $\mathrm{TiO}_{2}$ shell builds up a physical protective layer coated on the surface of the microemulsion droplets of lauric acid, which prevents the exudation of the melted lauric acid and the escape of flammable gas produced in the process of thermal decomposition [24].

Table 3. Comparison of thermal performances between the $\mathrm{LA} / \mathrm{TiO}_{2}$ microcapsules and other microcapsules in literatures

\begin{tabular}{|c|c|c|c|c|c|}
\hline MPCMs & $\begin{array}{c}\text { Melting } \\
\text { point, }{ }^{\circ} \mathrm{C}\end{array}$ & $\begin{array}{c}\text { Solidifying } \\
\text { point, }{ }^{\circ} \mathrm{C}\end{array}$ & $\begin{array}{c}\text { Melting } \\
\text { enthalpy, J/g }\end{array}$ & $\begin{array}{c}\text { Solidifying } \\
\text { enthalpy, J/g }\end{array}$ & Reference \\
\hline Lauric acid/Activated carbon (1:2) & 44.07 & 42.83 & 65.14 & 62.96 & {$[25]$} \\
\hline Docosane /PMMA & 41.00 & 40.60 & 54.60 & 48.70 & {$[26]$} \\
\hline Stearic acid (25 wt.\%)/ $/ \mathrm{TiO}_{2}$ & 53.84 & 53.31 & 47.82 & 45.60 & {$[24]$} \\
\hline Lauric acid (43.5 wt.\%)/ $\mathrm{TiO}_{2}$ & 44.39 & 43.64 & 67.54 & 65.17 & Present study \\
\hline
\end{tabular}


As listed in Table 4, the onset temperatures of the mass loss of the microcapsules are lower than that of the LA. This is owing to the evaporation of water and ethanol in the titanium dioxide shell [13]. In addition, the thermal decomposition temperature of the lauric acid in the microcapsules exceeds $200{ }^{\circ} \mathrm{C}$ while the operating temperature range of the composites is usually between $30{ }^{\circ} \mathrm{C}$ and $70^{\circ} \mathrm{C}$, so the prepared composites has desirable thermal stability and fire resistance in the filed of thermal energy storage.

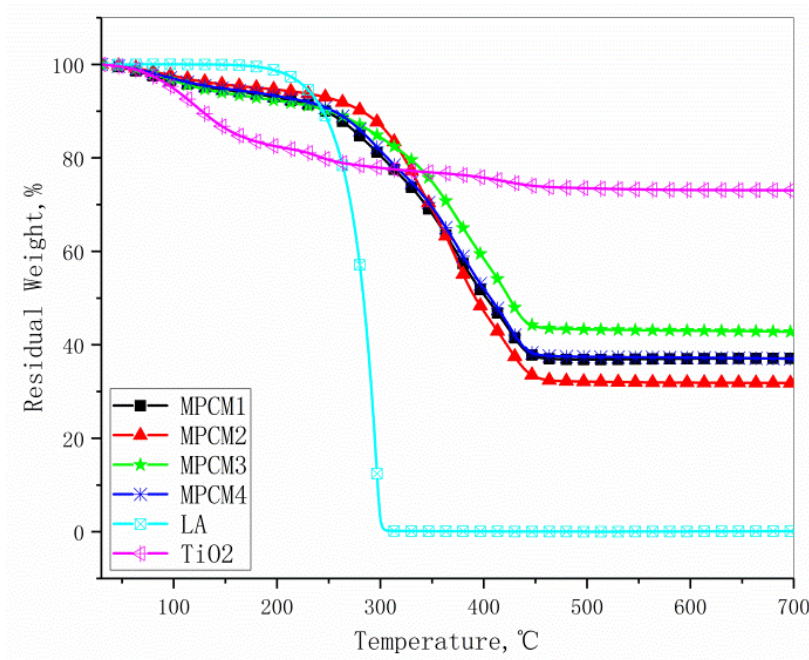

Fig. 6. TGA graphs of the lauric acid, $\mathrm{TiO}_{2}$, MPCM1, MPCM2, MPCM3 and MPCM4

Table 4. TGA data of the lauric acid and MPCM1-MPCM4

\begin{tabular}{|c|c|c|c|}
\hline Samples & $\mathrm{T}_{\text {onset}},{ }^{\circ} \mathrm{C}$ & $\mathrm{T}_{\text {peak }},{ }^{\circ} \mathrm{C}$ & $\begin{array}{c}\text { Percent mass } \\
\text { loss, } \%\left(700{ }^{\circ} \mathrm{C}\right)\end{array}$ \\
\hline Lauric acid & 200 & 373 & 0.11 \\
\hline $\mathrm{TiO}_{2}$ & 86 & 441 & 73.06 \\
\hline $\mathrm{MPCM} 1$ & 96 & 458 & 37.09 \\
\hline $\mathrm{MPCM} 2$ & 116 & 462 & 31.82 \\
\hline MPCM3 & 98 & 452 & 42.79 \\
\hline MPCM4 & 104 & 456 & 37.00 \\
\hline
\end{tabular}

\section{CONCLUSIONS}

A novel microencapsulated composite phase change material using lauric acid as core and $\mathrm{TiO}_{2}$ as shell was prepared by sol-gel method. The prepared composites were characterized by a series of methods, and the results obtained were as follows:

1. The results of FT-IR and FE-SEM denoted lauric acid was compatible with $\mathrm{TiO}_{2}$ each other and no chemical reaction occurred between them. Lauric acid microemulsion droplets were coated well into a spherical structure, which greatly increased the specific surface area of the composites. Meanwhile, $\mathrm{TiO} 2$ as the inorganic shell material is inherent with higher thermal conductivity than organic material, so that the heat transfer efficiency between the microcapsules and ambient air has been greatly improved.

2. According to the results of DSC and TGA, it is known that MPCM2 has a suitable phase transition temperature, good thermal stability and the phase enthalpy is larger than that of other three samples. MPCM 2 melted at $44.39{ }^{\circ} \mathrm{C}$ with a latent heat enthalpy of $67.54 \mathrm{~J} / \mathrm{g}$ and solidified at $43.64{ }^{\circ} \mathrm{C}$ with a latent solidification enthalpy of $65.17 \mathrm{~J} / \mathrm{g}$ as the microencapsulation ratio is $43.50 \%$. Therefore, it was selected as the most satisfactory sample for this experiment. In addition, the residual amount of $\mathrm{TiO}_{2}$ at $700{ }^{\circ} \mathrm{C}$ is still $73.06 \%$ from the thermal stability analysis. It is concluded that $\mathrm{TiO}_{2}$ prevents leakage of the melted lauric acid and possesses good thermal stability, which makes the thermal stability and fire resistance of the prepared microcapsules greatly enhanced. This is consistent with the results obtained from other literatures for the preparation of composite phase change materials with titanium dioxide as shell materials [24].

Based on the above results, it is concluded that the prepared microencapsulated composites have considerable thermal energy potential for solar energy storage systems and other potential applications such as electronic devices for cooling. In the next work, we will try to encapsulate the fatty acid eutectic with titanium dioxide, in order to obtain the microcapsuled composite phase change material with good thermal properties such as suitable phase transition temperature and strong heat storage capacity.

\section{Acknowledgments}

This work is supported by the Science and Technology Support Project of Jiangxi province (Grant No.20112BBE50031).

\section{REFERENCES}

1. Du, K., Calautit, J., Wang, Z.H., Wu, Y.P., Liu, H. A Review of the Applications of Phase Change Materials in Cooling, Heating and Power Generation in Different Temperature Ranges Applied Energy 220 2018: pp. $242-273$. https://doi.org/10.1016/j.apenergy.2018.03.005

2. Shalaby, S.M., Bek, M.A., El-Sebaii, A.A. Solar Dryers with PCM as Energy Storage Medium: A Review Renewable \& Sustainable Energy Reviews $33(2)$ 2014: pp. $110-116$.

https://doi.org/10.1016/j.rser.2014.01.073

3. Zhou, Z.H., Zhang, Z.M., Zuo, J., Huang, K., Zhang, L.Y. Phase Change Materials for Solar Thermal Energy Storage in Residential Buildings in Cold Climate Renewable \& Sustainable Energy Reviews 48 2015: pp. $692-703$. https://doi.org/10.1016/j.rser.2015.04.048

4. Fang, G.Y., Tang, F., Cao, L. Preparation, Thermal Properties and Applications of Shape-Stabilized Thermal Energy Storage Materials Renewable \& Sustainable Energy Reviews 40 (C) 2014: pp. 237-259. https://doi.org/10.1016/j.rser.2014.07.179

5. Ma, T, Yang, H.X., Zhang, Y.P., Liu, L., Wang, X. Using Phase Change Materials in Photovoltaic Systems for Thermal Regulation and Electrical Efficiency Improvement: A Review and Outlook Renewable \& Sustainable Energy Reviews 43 2015: pp. 1273-1284. https://doi.org/10.1016/j.rser.2014.12.003

6. Belman-Flores, J.M., Rodríguez-Muñoz, A.P., Camacho-Vázquez, G.
Barroso-Maldonado, J.M., 
Enhancements in Domestic Refrigeration, Approaching a Sustainable Refrigerator - A Review Renewable \& Sustainable Energy Reviews $51 \quad$ 2015: pp. 955-968. https://doi.org/10.1016/j.rser.2015.07.003

7. Muratore, C., Aouadi, S.M., Voevodin, A.A. Embedded Phase Change Material Microinclusions for Thermal Control of Surfaces Surface \& Coatings Technology 206 (23) 2012: pp. $4828-4832$. https://doi.org/10.1016/j.surfcoat.2012.05.030

8. Papadimitratos, A., Sobhansarbandi, S., Pozdin, V., Zakhidov, A., Hassanipour, F. Evacuated Tube Solar Collectors Integrated with Phase Change Materials Solar Energy 129 2016: pp. 10-19.

https://doi.org/10.1016/j.solener.2015.12.040

9. Alva, G., Lin, Y.X., Fang, G.Y. An Overview of Thermal Energy Storage Systems Energy 144 2018: pp. $341-378$. https://doi.org/10.1016/j.energy.2017.12.037

10. Chen, Z., Feng, S., Cao, L., Fang, G.Y. Synthesis and Thermal Properties of Shape-Stabilized Lauric Acid/Activated Carbon Composites as Phase Change Materials for Thermal Energy Storage Solar Energy Materials \& Solar Cells 102 (7) 2012: pp. 131-136. http://dx.doi.org/10.1016/j.solmat.2012.03.013

11. Sarı, A., Alkan, C., Karaipekli, A. Preparation, Characterization and Thermal Properties of PMMA/ N -heptadecane Microcapsules as Novel Solid-Liquid MicroPCM for Thermal Energy Storage Applied Energy 87 (5) 2010: pp. 1529-1534. https://doi.org/10.1016/j.enconman.2010.07.047

12. Salaün, F., Bedek, G., Devaux, E., Dupont, D., Gengembre, L. Microencapsulation of a Cooling Agent by Interfacial Polymerization: Influence of The Parameters of Encapsulation on Poly(urethane-urea) Microparticles Characteristics Journal of Membrane Science 370 (1) 2011: pp. 23-33.

https://doi.org/10.1016/j.memsci.2010.11.033

13. Fang, G.Y., Li, H., Liu, X. Preparation and Properties of Lauric Acid/Silicon Dioxide Composites as Form-Stable Phase Change Materials for Thermal Energy Storage Materials Chemistry \& Physics 122 (2) 2010: pp. $533-536$. https://doi.org/10.1016/j.matchemphys.2010.03.042

14. Wu, H.T., Yang, M.W. Precipitation Kinetics of PMMA Sub-Micrometric Particles with a Supercritical Assisted-Atomization Process Journal of Supercritical Fluids 59 (6) 2011: pp. 98-107. https://doi.org/10.1016/j.supflu.2011.08.001

15. Santos, M.G., Bozza, F.T., Thomazini, M., Carmen, S., Favarotrindade, C.S. Microencapsulation of Xylitol by Double Emulsion followed by Complex Coacervation Food Chemistry $171 \quad$ 2015: pp. 32-39. https://doi.org/10.1016/j.foodchem.2014.08.093

16. Cao, L., Su, D., Tang, F., Fang, G.Y. Properties Evaluation and Applications of Thermal Energy Storage Materials in Buildings Renewable \& Sustainable Energy Reviews 48 2015: pp. 500-522. http://dx.doi.org/10.1016/j.rser.2015.04.041

17. Chen, Z., Fang, G.Y. Preparation and Heat Transfer Characteristics of Microencapsulated Phase Change Material Slurry: A Review Renewable \& Sustainable Energy Reviews 15 (9) 2011: pp. 4624-4632. https://doi.org/10.1016/j.rser.2011.07.090

18. Zhang, H.Z., Wang, X.D., Wu, D.Z. Silica Encapsulation of N-octadecane via Sol-gel Process: a Novel Microencapsulated Phase-Change Material with Enhanced Thermal Conductivity and Performance Journal of Colloid \& Interface Science 343 (1) 2010: pp. 246-255. https://doi.org/10.1016/j.jcis.2009.11.036

19. Chen, Z., Cao, L., Fang, G.Y., Shan, F. Synthesis and Characterization of Microencapsulated Paraffin Microcapsules as Shape-Stabilized Thermal Energy Storage Materials Nanoscale \& Microscale Thermophysical Engineering 17 (2) 2013: pp. 112-123. https://doi.org/10.1080/15567265.2012.761305

20. Yu, S.Y., Wang, X.D., Wu, D.Z. Microencapsulation of N -octadecane Phase Change Material with Calcium Carbonate Shell for Enhancement of Thermal Conductivity and Serving Durability: Synthesis, Microstructure, and Performance Evaluation Applied Energy 114 (2) 2014: pp. $632-643$. https://doi.org/10.1016/j.apenergy.2013.10.029

21. Pan, L., Tao, Q.H., Zhang, S.D., Wang, S.H., Zhang, J., Wang, S.H., Wang, Z.Y., Zhang, Z.P. Preparation, Characterization and Thermal Properties of Micro-Encapsulated Phase Change Materials Solar Energy Materials \& Solar Cells 98 (1) 2012: pp. 66-70. https://doi.org/10.1016/j.solmat.2011.09.020

22. Cahill, D.G., Allen, T.H. Thermal Conductivity of Sputtered and Evaporated $\mathrm{SiO}_{2}$ and $\mathrm{TiO}_{2}$ Optical Coatings Applied Physics Letters 65 (3) 1994: pp. 309-311. https://doi.org/10.1063/1.112355

23. Touloukian, Y.S. Thermophysical Properties of Matter Europhysics News 39 (5) 1986: pp. 19-21.

24. Tang, F., Cao, L., Fang, G.Y. Preparation and Thermal Properties of Stearic Acid/Titanium Dioxide Composites as Shape-Stabilized Phase Change Materials for Building Thermal Energy Storage Energy and Buildings 80 2014: pp. $352-357$. https://doi.org/10.1016/j.enbuild.2014.05.030

25. Chen, Z., Shan, F., Cao, L., Fang, G.Y. Synthesis and Thermal Properties of Shape-Stabilized Lauric Acid/ Activated Carbon Composites as Phase Change Materials for Thermal Energy Storage Solar Energy Materials \& Solar Cells $102.7 \quad$ 2012: pp. 131-136. https://doi.org/10.1016/j.solmat.2012.03.013

26. Alkan, C., Sari, A., Karaipekli, A., Uzun, O. Preparation, Characterization and Thermal Properties of Microencapsulated Phase Change Material for Thermal Energy Storage Solar Energy Materials and Solar Cells 93 2009: pp. 143-147.

https://doi.org/10.1016/j.enconman.2010.07.047 